\title{
EDUCAÇÃO PROFISSIONAL A DISTÂNCIA: HISTÓRICO, ANÁLISE E TENDÊNCIAS
}

\author{
M. G. M. MACEDO \\ Instituto Federal de Educação, Ciência e Tecnologia do Rio Grande do Norte \\ marcus.macedo@ifrn.edu.br*
}

Artigo submetido em outubro/2013 e aceito em dezembro/2013

DOI: $10.15628 /$ rbept.2013.3477

\section{RESUMO}

Este estudo tem a finalidade de analisar e discutir as possibilidades da educação a distância na educação profissional, face o caráter de desenvolvimento da educação a distância em função de cursos de qualificação para o trabalho. Perpassando pela historicidade da educação profissional, dos modos de produção capitalistas fordista e toyotista e do modelo atual de educação on-line, verifica-se que a educação a distância permite a formação de um aluno flexível, polivalente, a um custo reduzido, gerando economias de escala para as escolas, para uma indústria flexível, exigente e moderna. Ainda, haverá uma tendência de substituição do ensino presencial pelo Blended Learning, através de vídeo-aulas e objetos de aprendizagem on-line, precarizando o trabalho docente, despolitizando os estudantes, submissos ao ideário capitalista de polivalência e qualidade.

PALAVRAS-CHAVE: Educação a distância, trabalho, toyotismo.

\section{PROFESSIONAL EDUCATION DISTANCE: HISTORY, ANALYSIS AND TRENDS}

\begin{abstract}
This study aim to analyze and discuss the possibilities of distance education in vocational schools, given the distance education development targeting training courses for workers. Running along the historicity of vocational education, fordism and Toyotism production ways and the current model of e-learning, it appears that the distance allows the formation of a flexible student, ready for multipurpose tasks, at a reduced cost,
\end{abstract}

generating economies of scale for organizations, for a flexible, demanding and modern industry. Still, there will be a tendency to replace the regular education for the blended learning, through video lessons and online learning objects, threating the teacher profession, depoliticizing students, submissive to the capitalist ideology of versatility and quality.

KEYWORDS: distance education, work, toyotism. 


\section{INTRODUÇÃO}

A educação profissional, entendida como educação para o trabalho na indústria e no setor de serviços, está intimamente ligada aos anseios do capital industrial, marcados em sua história por modos de organização distintos, com filosofias antagônicas, mas que sempre tiveram os mesmos objetivos: diminuição do tempo e dos custos de produção, com maximização das receitas. Logo, a educação de massa está atrelada as imposições de ordem econômica.

Neste trabalho, através de análise bibliográfica e documental, explorando textos da educação profissional, da educação à distância, de engenharia de produção e do modo de produção just-in-time, será realizada uma análise e discussão das vantagens e limitações da aplicação da educação a distância na educação profissional, explicitando características comuns ao modelo Toyota de produção flexível. Ainda, serão apontadas tendências do uso da educação a distância na educação profissional.

\section{RELAÇÕES ENTRE O MODO DE PRODUÇÃO CAPITALISTA E OS SISTEMAS EDUCACIONAIS}

Toda a pesquisa e o sistema escolar capitalista precisam estar atrelados ao capital, na ordem da rentabilização e formação de uma massa de indivíduos aptos à produção capitalista, com mão de obra especializada, mas sem formação geral e política (GADOTTI, 1982). Assim, a escola do século XX e XXI tem sido aperfeiçoada, com revisão de cursos e currículos, para atender as demandas da indústria e do capital. Nesse contexto, se insere a educação profissional, destinada precipuamente à formação para o trabalho.

Anteriormente, os pensadores da educação presencial, no sentido de atenderem o maior número de alunos, utilizaram as ideias de Henry Ford para a escolarização em massa. (O'LOONEY, 1993). O fordismo possui como características: produto padrão produzido a grandes volumes; trabalhadores com baixo conhecimento do processo produtivo total, mas especializados em uma parte do processo, executando tarefas rotineiras e relativamente simples; separação entre o gerenciamento, equipe de projeto e trabalhadores da produção. Desse modo, foi instalado no ambiente escolar um modelo de produção linear, seriado, com a desespecialização dos trabalhadores para redução dos custos com mão de obra, tendência de separação daqueles que processam informações, o ensino, com os que produzem as informações através da pesquisa acadêmica, e a centralização geográfica de recursos educacionais em grandes instalações de ensino. Essas características são marcantes na educação profissional e no ensino superior público na modalidade presencial.

O sistema de produção fordista foi hegemônico pós II Guerra Mundial. Para formar trabalhadores aptos às linhas de produção, o sistema educacional se dava através de dois tipos de ensino: um ensino deveria ser executado para formar operários com habilidades mínimas para a indústria, ou seja, uma educação pobre, que ensinasse uma mínima leitura, escrita e de operações aritméticas básicas; e um outro ensino, rico em conteúdos e ócio, preparando para o comando da classe dominante, para os níveis gerenciais da indústria, ou para as profissões liberais 1, ou seja, a

\footnotetext{
${ }^{1}$ São àqueles profissionais, trabalhadores, que podem exercer com liberdade e autonomia a sua profissão, decorrente de formação técnica ou superior específica, legalmente reconhecida, formação essa advinda de estudos e de conhecimentos técnicos e científicos. O exercício de sua profissão pode ser dado com ou sem vínculo empregatício
} 
educação das elites. Segundo Gadotti (2012) é uma educação que prepara os mais pobres para as atividades manuais e a superexploração. Enquanto as elites são preparadas para governar, uma massa quase analfabeta é preparada para a subserviência, com meia educação.

Como na indústria de Ford a filosofia era a de "um homem, uma máquina", a educação profissional logo tratou de preparar trabalhadores com essas características, ensinando ofícios, especializando os discentes em uma atividade específica para que executassem suas tarefas o mais rápido possível, produzindo um maior número de peças, bens ou serviços por hora trabalhada. Nesse modo de produção, as habilidades do trabalhador eram predominantemente tácitas, advindas pelo empirismo que da relação com o conhecimento sistematizado (KUENZER, 2007).

As escolas de educação profissional também se espelhavam nas grandes indústrias da época fordista, utilizando grandes instalações e recursos, onde todos iniciavam as atividades no mesmo horário, ao toque do sinal, e executavam as mesmas tarefas, dividida em séries. Os laboratórios ocupavam grandes galpões, cheios de máquinas e equipamentos, funcionando os três turnos, como as fábricas.

Todavia, após a II guerra mundial surgiu um novo modelo de produção pressionado pelas necessidades japonesas. Dada as condições de recuperação da economia japonesa e suas características naturais, seria necessário promover no país uma nova forma de organização do trabalho, mais flexível e que exigisse menor concentração de estoques, pois o mercado era pequeno, capital e matéria-prima eram escassos (FUTATA, 2005).

Logo, de modo a tornar a indústria do Japão competitiva, Taiichi Ohno implementou na indústria automobilística de seu país, um sistema de produção diverso ao modelo de Henry Ford. Nas instalações fabris da Toyota ele introduziu máquinas flexíveis, que poderiam ter suas ferramentas modificadas rapidamente para produção de diversos produtos. Também, reduziu o tamanho dos armazéns de matérias primas e de estoques, criando o tão difundido sistema Just-intime2 pois os produtos deveriam ser produzidos após a demanda efetiva do mercado e ter alta rotatividade. Por fim, retiraram todos os elementos que não agregavam valor aos produtos, desde etapas no processo de manufatura, até acessórios nos produtos, diminuindo os desperdícios.

Para o próprio Ohno (1997, p. 24) “o principal objetivo do sistema Toyota de produção é produzir muitos modelos em pequenas quantidades". Para isso, ela se utiliza de um sistema "puxado", no qual o processo final (ou posterior) retira quantidades necessárias do processo precedente, e este procedimento é repetido por todos os processos intermediários (OHNO, 1997. SLACK, 2009).

Como o objetivo era produzir mais com menos recursos, foi instalada a automatização dos processos, com substituição de mão-de-obra por máquinas "inteligentes", proporcionadas pelo desenvolvimento da eletrônica e da computação. Com essas mudanças nos processos produtivos,

\footnotetext{
específico, mas sempre regulamentado por organismos fiscalizadores do exercício profissional. Exemplos são: médicos, advogados, dentistas, arquitetos, engenheiros, contadores, corretores de imóveis, arquitetos, etc.

2 Just-in-time: O just-in-time (JIT) é uma abordagem disciplinada, que visa aprimorar a produtividade global e eliminar os desperdícios. Ela possibilita a produção eficaz em termos de custo, assim como o fornecimento apenas da quantidade correta, no momento e local corretos, utilizando o mínimo de instalações, equipamentos, materiais e recursos humanos. O JIT é dependente do equilíbrio entre a flexibilidade do fornecedor e a flexibilidade do usuário. Ele é alcançado por meio da aplicação de elementos que requerem um envolvimento total dos funcionários e trabalho em equipe. Uma filosofia chave do JIT é a simplificação. (SLACK, 2009, p. 452).
} 
consolidada mundialmente a partir do final dos anos 70, um trabalhador do chão de fábrica deveria ser responsável por várias máquinas. Nesse sentido, a educação profissional deve se alinhar as demandas industriais em prol dos objetivos da produtividade, discutindo as relações entre as empresas e as escolas, para formar um novo trabalhador, polivalente, flexível e capaz de adquirir competências e habilidades em tempo reduzido (STÊNICO E SILVA, 2014). A esse respeito, Frigotto (2007, p. 523) elucida:

Trata-se de uma educação de 'qualidade total'. Vale dizer, aquela que possui as 'competências' que se enquadram na lógica do 'cidadão produtivo' prontamente adaptável e que produz em tempo mínimo, qualidade máxima e cuja mercadoria ou serviço se realizem no mercado imediatamente.

Tecnologicamente, as indústrias avançam mais rapidamente que os sistemas educacionais. Mas a partir da década de 90, a educação a distância (EAD) ganha uma nova dimensão, com o advento da rede mundial de computadores, permitindo um maior intercâmbio de informações, interações através de e-mail e "chats", passando a representar, no contexto escolar, a educação enxuta, seguindo os preceitos da filosofia Just-in-time.

\section{CONEXÕES DA EDUCAÇÃO PROFISSIONAL COM A EDUCAÇÃO A DISTÂNCIA}

A educação profissional possui como premissas a centralidade do trabalho como princípio educativo e a indissociabilidade entre teoria e prática, desde a formação inicial e continuada de trabalhadores, objetivando o desenvolvimento de aptidões para a vida produtiva e social (BRASIL, 2004).

Não se pode negligenciar que a educação a distância no Brasil teve sua raiz na educação profissional. Cursos por correspondência eram realizados para a profissionalização de datilógrafos pelo Jornal do Brasil (1904), e posteriormente cursos variados eram ofertados pelo Instituto Monitor (1939) e pelo Instituto Universal Brasileiro (1941). Com o advento do rádio, foi criada a Universidade do Ar, patrocinada pelo Serviço Nacional de Aprendizagem Comercial - SENAC - em 1947 (ALVES, 2011). Como cursos profissionalizantes são mais curtos e oferecem menor grau de complexidade, a EAD é vista como uma alternativa de baixo custo para a formação para o trabalho, servindo aos interesses burgueses.

Dentro da dicotomia existente no termo trabalho, a educação profissional se destina à preparação para o trabalho tangível, produtor de bens e serviços, enquanto a educação superior universitária está para a formação ao trabalho intangível, intelectual, voltado ao desenvolvimento científico e tecnológico, ao planejamento e supervisão.

Sob a ótica social, a EAD mediada pelas novas tecnologias de informação (TICs) e comunicação fomenta a melhoria dos níveis educacionais, com ampliação da oferta de ensino, superando entraves geográficos, democratizando o ensino formal e não-formal nos distintos níveis. Tais benesses são utilizadas com fins políticos. Sob a ótica econômica, é uma forma de ensino a qual permite educar o maior número de pessoas com o menor custo por educando, 
gerando economias de escala ${ }^{3}$, com menor utilização de horas de trabalho, salas de aula e não requer grandes instalações físicas e consumo de materiais (HJELTNES; HANSSON, 2005).

Assim, pode-se afirmar que o caráter profissional fornecido pela EAD atual tende a substituição do trabalho vivo, executado por professores, pelo trabalho morto. Com repositório de vídeo-aulas e objetos de aprendizagem, o papel do professor, entendido como aquele que planeja, executa e avalia, se faz cada vez menos essencial. O vídeo educacional, a educação morta, pode ser replicado milhões de vezes. A Khan Academy, dentre inúmeras instituições, já iniciou um projeto nesse sentido. Segundo seu idealizador, Salman Khan, os alunos podem assistir livremente as aulas disponibilizadas em seu sítio através dos computadores em um momento prévio. Em seguida, necessitam ir às instalações escolares apenas para serem tutorados pelos professores. Logo, todos os discentes podem frequentar o mesmo local, sem a necessidade de paredes, e os professores multiespecializados passam a circular entre todos os alunos, ajudando-os no cumprimento das tarefas. Isso pode acelerar o tempo total de atravessamento do aluno pelos conteúdos previstos para determinada série. Acerca desse projeto, Salman Khan descreve como "educação classe mundial".

A substituição dos docentes pela tecnologia também pode ser verificada nos mecanismos de aprendizagem colaborativa propiciado pelas TICs: os wikis e fóruns de discussão. O trabalho cooperativo, métodos, técnicas e ferramentas são necessidades do capitalismo industrial e se impõem na esfera educacional (ASSIS; PADILHA, 2004).

\section{PERSPECTIVAS DA EDUCAÇÃO PROFISSIONAL NA MODALIDADE À DISTÂNCIA}

Por regra, a educação profissional brasileira ainda está arraigada ao ensino, que põe o foco no docente, em detrimento da aprendizagem, focada no aluno. $O$ processo educativo a essa maneira gera desperdício, em conflito a um tecido social mais consciente e propenso a racionalização de recursos. Quando a maior parte da população dominar as práticas da leitura, escrita, e estiverem incluídas digitalmente, a educação profissional à distância mediada por ambientes virtuais de aprendizagem tenderão a se tornar o comum, em detrimento dos estabelecimentos destinados à educação presencial.

Partindo do ideário da educação enxuta, a educação profissional deverá assistir nos anos seguintes, a uma redução dos custos devido à menor utilização dos recursos humanos e materiais. Os cursos, independente de área do conhecimento, deverão ter atividades teóricas expositivas por meio de textos e vídeos disponíveis on-line. As atividades práticas laboratoriais, dado a indissociabilidade entre teoria e prática da educação profissional, serão realizadas em instalações menores, com prévio agendamento, onde haverá tutores e instrutores para auxílio, os quais também serão avaliadores do desempenho prático dos discentes, mas serão alheios à exposição teórica dos conteúdos. Esses padrões estão em conformidade com os objetivos apregoados pela Khan Academy. Quiçá, as atividades práticas poderão ser desenvolvidas dentro da própria indústria, com planejamento e instalações adequadas à segurança dos discentes. Como

\footnotetext{
${ }^{3}$ Economia de escala permite a máxima utilização dos fatores de produção envolvidos no processo, minimizando os custos de produção e o incremento de bens e serviços. Ela ocorre quando a expansão da capacidade de produção de uma indústria provoca um aumento na quantidade total produzida sem um aumento proporcional no custo de produção. Como resultado, o aumento da produção é acompanhado por uma diminuição do custo médio por produto ou serviço (PASSOS, 2011).
} 
consequência, o modelo adotado pela educação profissional será o de Blended Learning, o qual requer momentos presenciais e não-presenciais, com predominância destes (MATTAR, 2011).

Deste modo, ocorrerá a fragmentação do papel do professor. Essa mão de obra escolar, alinhada aos interesses econômicos, sofrerá uma divisão em uma série discreta de tarefas, podendo ser executada por diferentes pessoas. A divisão do processo educacional em componentes menores resulta na desintegração da profissão de professor, da mesma maneira que ocorre com um operário quando uma especialização é substituída pela introdução de máquinas na mesma função (MATTAR, 2011). Cabe ressaltar que a divisão do trabalho docente levará à precarização (LAPA, PRETTO, 2010), com redução dos direitos dos professores, diminuição de salários, ausência de vínculos entre a escola e o tutor, além da ampliação da jornada laboral.

Haverá também a flexibilização dos currículos, fornecendo maior possibilidade para os discentes escolherem as disciplinas e desenvolverem as aptidões conforme os seus interesses.

Como o objetivo é a minimização dos desperdícios, não haverá momentos presenciais para o debate de ideias. Assim, a escola enxuta deixará de ser também um espaço de conflito, de debate sobre as questões profissionais. Nela, o debate estará presente em fóruns de discussão, nas redes sociais, desarticulando e desmobilizando os movimentos sociais da classe trabalhadora, em nome da flexibilidade e contra o desperdício temporal.

A despeito da corrente de oposição arraigada a educação profissional fordista, este será o rumo traçado e perseguido pela educação profissional do século XXI.

\section{CONSIDERAÇÕES FINAIS}

A educação profissional na modalidade à distância é meio de democratização do ensino, qualificando para o trabalho. Utilizando recursos colaborativos on-line, como os ambientes virtuais de aprendizagem, é possível mitigar o descompasso entre o desenvolvimento global das tecnologias e empresas e o sistema educacional vocacional.

A expansão do ensino profissionalizante, tanto na modalidade presencial como na modalidade à distância, visa atender a demanda do mercado por pessoas qualificadas, carregando consigo resquícios de discriminação social, baseado numa educação classista. $\mathrm{O}$ caso das escolas técnicas abertas, objetivando capacitar jovens adultos para o ingresso no mercado de trabalho, como garantia do emprego e renda, é uma educação voltada para as camadas mais populares, para um mercado que exige polivalência, capacidade de raciocínio e decisão e execução de operações complexas determinadas pelo modelo Toyota de produção flexível.

A flexibilidade da EAD profissionalizante entrega ao mercado trabalhadores capacitados à um baixo custo, despolitizados e flexíveis, com ótima sujeição ao ideário capitalista de polivalência e qualidade, reduzindo as instalações escolares, dividindo o papel do professor, ameaçando e precarizando as condições laborais destes profissionais da educação.

\section{REFERÊNCIAS}

1. ALVES, Lucineia. Educação a distância: conceitos e histórias no Brasil e no mundo. Revista Brasileira de Aprendizagem Aberta e a Distância. V. 10, p. 83-92. 2011. 
2. ASSIS, Marta Maria da Silva; PADILHA, Anna Maria Lunardi. Pedagogia da Cooperação: a Cartilha Toyotista na Educação. Revista Linhas, v. 5, n. 2. Piracicaba, 2004. Disponível em: < http://www.periodicos.udesc.br/index.php/linhas/article/viewFile/1221/1035 > Acesso em: 30 março de 2013.

3. BRASIL. Decreto no 5.154 de 23 de julho de 2004: Regulamenta o $\S 20$ do art. 36 e os arts. 39 a 41 da Lei no 9.394, de 20 de dezembro de 1996, que estabelece as diretrizes e bases da educação nacional, e dá outras providências. Diário Oficial da União, 26 de Julho de 2004.

4. FRIGOTTO, Gaudêncio. Educação profissional e capitalismo dependente: o enigma da falta e sobra de profissionais qualificados. Trabalho, Educação e Saúde, v.5, n.3, p.521-536. Novembro de 2007.

5. FUTATA, Marli Delmonico de Araújo. Breve análise sobre o toyotismo: modelo japonês de produção. Revista espaço acadêmico, № 47, Abril de 2005 . Disponível em: <http://www.espacoacademico.com.br/047/47cfutata.htm> Acesso em 18/09/2012.

6. GADOTTI, Moacir. Educação e poder: introdução à pedagogia do conflito. Editora Cortez. São Paulo, 1982.

7. GADOTTI, Moacir. Trabalho e educação numa perspectiva emancipatória. Il fórum mundial de educação profissional e tecnológica. Florianópolis. Junho de 2012. Disponível em: < http://2sitefmept.ifsc.edu.br/ > Acesso em: 02 de dezembro de 2012.

8. HJELTNES, Tor Atle. HANSSON, Borje. Cost effectiveness and cost efficiency in e-learning. Faculdade de Tecnologia da Informação e Aprendizagem on-line da Universidade de SorTrondelag. Noruega, 2005.

9. KUENZER, Acacia Zeneida. Reforma da educação profissional ou ajuste ao regime de acumulação flexível? Trabalho, Educação e Saúde, v.5, n.3, p.491-508. Novembro de 2007.

10. LAPA, Andrea; PRETTO, Nelson de Luca. Educação a Distância e Precarização do Trabalho Docente. Em Aberto, Brasília, n.84, novembro de 2010.

11. MATTAR, João. Guia de Educação a Distância. Cengage Learning: São Paulo, 2011.

12. OHNO, Taiichi. O sistema Toyota de produção: além da produção em larga escala. 1 ed. Porto Alegre: Artes Médicas, 1997.

13. O'LOONEY, John. Redesigning the work of education. The Phi Delta Kappan, 1993. v. 74, n. 5, p. 375-381. Disponível em: <http://www.jstor.org/ > Acesso em: 09 de junho de 2013.

14. PASSOS, Carlos Roberto Martins; NOGAMI, Otto. Princípios de Economia. 5 ed. Cengage Learning, São Paulo, 2011.

15. SLACK, Nigel, et al. Administração da produção. 3. ed. Editora Atlas. São Paulo, 2009.

16. STÊNICO, Joselaine Andréia de Godoy; SILVA, Joyce Mary Adam de Paula. Educação Profissional Brasileira: análises, discussões e tendências. Revista Espacios, v. 35, n. 12, p. 1-8, 2014. 